\title{
Research impact for (mental) health policy
}

Kristel Alla, Wayne D. Hall, Harvey A. Whiteford, Brian W. Head, Carla S. Meurk

\section{Source}

Kristel Alla, Wayne D. Hall, Harvey A. Whiteford, Brian W. Head, Carla S. Meurk. (2017).

How do we define the policy impact of public health research? A systematic review.

Health Res Policy Sys, vol. 15 (1). doi:10.1186/s12961-017-0247-z.

Research impact is a direct or indirect contribution of research processes or outputs that have informed (or resulted in) the development of new (mental) health policy/practices, or revisions of existing (mental) health policy/practices, at various levels of governance (international, national, state, local, organisational, health unit). 